\title{
Effect of electroless coating parameters and ceramic particle size on fabrication of a uniform $\mathrm{Ni}-\mathrm{P}$ coating on $\mathrm{SiC}$ particles
}

\author{
N. Beigi Khosroshahi ${ }^{a}$, R. Azari Khosroshahi ${ }^{a}$, R. Taherzadeh Mousavian, ${ }^{\text {b,n }}$, D. Brabazon ${ }^{\text {c }}$ \\ ${ }^{a}$ Faculty of Materials Engineering, Sahand University of echnology, Iran \\ ${ }^{b}$ Department of Metallurgy, Zanjan Branch, Islamic Azad University, Zanjan, Iran \\ ${ }^{c}$ Advanced Processing Technology Research Centre, School of Mechanical \& Manufacturing Engineering, \\ Dublin City University, Dublin, 9, Ireland
}

\begin{abstract}
The formation of a uniform nickel phosphorous (Ni-P) electroless (EL) coating on micronsized $\mathrm{SiC}$ particles was investigated in this study. Metal coated ceramic particles could be used in applications including as the fabrication of cast metal matrix composites.Such ceramic particles have a better wettability in molten metal. In this work, the effects of EL coating parameters, SiC particle size and morphology on the coating uniformity and mechanical bonding at the $\mathrm{SiC} / \mathrm{Ni}-\mathrm{P}$ interface were studied. The results indicated that etching treatment was very effective (especially for coarse powders) on the mechanical bonding at the interface. Theoptimum values of bath temperature and $\mathrm{pH}$ were determined to be $50+\_2{ }^{0} \mathrm{C}$ and 8+_0.2, respectively. The best uniformity and mechanical bonding were obtained for $\mathrm{SiC}$ particles with average particle size of $80 \mu \mathrm{m}$ (considered relatively as coarse powders in this study). The ball milling of SiC particles (with the average particle size of $80 \mu \mathrm{m}$ ) for $1 \mathrm{~h}$ led to the formation of a multi-modal particle size distribution which resulted in a non-uniform quality of particulate coating. The larger SiC particles after ball milling were more completely covered by the $\mathrm{Ni}-\mathrm{P}$ coating compared to the smaller more fragmented particles. The smaller ceramic particles processed via Ni-P EL coating lead to formation of segregated clusters of $\mathrm{Ni}-\mathrm{P}$ and therefore such ceramic particles contained many uncoated parts.
\end{abstract}

Keywords: Ball mill; Electroless; Nickel phosphorous (Ni-P); SEM; SiC particles

\section{Introduction}

Metal-coated ceramic particles are composite powders with a ceramic core and metallic shell. These particles are more suitable for electrical, magnetic and chemical properties and have improved wettability compared to non-coated particles [1-11]. Poor binding between molten metal and non-coated ceramic particles is a consequence of their low wetting behavior. If high processing temperatures are used in composites manufacturing, interfacial degradation reactions can occur. Metallic coatings of nickel or copper are used to improve the wettability of reinforcement within the matrix material and thereby cause a good bond between matrix alloy and reinforcement. Metallic coatings have been reported to be achieved via various methods. Among these methods, the electroless nickel (EN) coating of the reinforcement is a simple, low-cost and an easy to use process. This process has been successfully applied to prevent undesired interfacial reactions and promote the wettability through increasing the overall surface energy of the reinforcement [1-8]. 
$\mathrm{EN}$ is an autocatalytic chemical reduction process in which the reducing agent is oxidized and $\mathrm{Ni}^{2 \mathrm{~b}}$ ions are deposited (reduced) on the substrate surface. Once the first layer of $\mathrm{Ni}$ is deposited, it acts as a catalyst for the process. The vast majority of EN coatings are deposited by catalytic reduction of nickel ions with sodium hypophosphite $\left(\mathrm{NaH}_{2} \mathrm{PO}_{2}\right)$.

Hypophosphite is one of the strongest reducing agents for the electroless Ni-P coating process which is much cheaper than electroless $\mathrm{Ni}-\mathrm{B}$ coatings [9-15]. Several theories were proposed for the mechanism of the electroless nickel process using hypophosphite as a reducing agent. Brenner and Riddell suggested a well-known mechanism in this regard [12]. Full details of this mechanism have been reported elsewhere [11].

Recently, some researchers have reported the effect of various parameters on the adhesion, uniformity, and thickness of Ni-P layer on ceramic particles. Kilicarslan et al. reported that electroless nickel coating of the coarse $\mathrm{B}_{4} \mathrm{C}$ particles ( with an average particle size of $93 \mu \mathrm{m}$ ) resulted in better surface quality as compared to the fine $\mathrm{B}_{4} \mathrm{C}$ particles (with an average particle size of $32 \mu \mathrm{m}$ ) [9]. They have used a constant $\mathrm{pH}$ and bath temperature as well as the same pre-treatment condition. Hajizamani et al. reported of the formation of $\mathrm{Ni}_{3} \mathrm{P}$ nano-scale layer on $\mathrm{B}_{4} \mathrm{C}$ nanoparticles in acidic bath using a constant $\mathrm{pH}$ and bath temperature as well as the same pre-treatment condition [10]. Their results were not in agreement with a study be Kilicarslan et al. [9], in which it was found that fine powders could not be covered completely by nickel coating. They used an attrition ball-mill to reduce the particle size of $\mathrm{B}_{4} \mathrm{C}$ via continuous fragmentation of ceramic brittle powders. The ball-milling (mechanical alloying, MA) process is a wellknown method for metallic or ceramic based powders, in which fragmentation and/or mechanical activation occur. In fact, MA is a unique process in that a solid state reaction takes place between the fresh powder surfaces of the reactant materials at room temperature. Consequently, it can be used to produce alloys and compounds that are difficult or impossible to be obtained by using conventional melting and casting techniques [16]. Therefore, it is valuable to assess the effect on coating efficiency of combining the ballmilling and EN processes.In this study, micron-sized SiC ceramic powders were used for EN coating. The effect of $\mathrm{pH}$, bath temperature, etching pretreatment, and the particle size as well as ball-milling of $\mathrm{SiC}$ powders was studied on the uniformity, mechanical bonding, mass gain $\%$, and the deposition rate of the EN coatings.

\section{Experimental procedures}

\subsection{Starting materials}

In order to investigate the effect of ceramic particle size and morphology, three kinds of SiC powders were used in this study. The as-received $\mathrm{SiC}$ powders used in this study were in two forms: (i) $99.5 \%$ purity with an average particle size of $80 \mu \mathrm{m}$; and ( ii ) $99.5 \%$ purity with an average particle size of $10 \mu \mathrm{m}$. A third form of the SiC powders was obtained via ball-milling of the SiC powder with an average particle size of $80 \mu \mathrm{m}$ (form i) using a planetary highenergy ball mill. For this purpose, alumina balls with $7 \mathrm{~mm}$ diameter were used and the ball to powder weight ratio was 5:1. The powders were ball-milled for $1 \mathrm{~h}$ using a high-purity argon $(99.99 \%)$ atmosphere with the rotating speed of $250 \mathrm{rpm}$.

Fig. 1 shows the morphology of the three kinds of SiC powder forms used in this study. Both $\mathrm{SiC}$ as-received powder particles have sharp corners, see Fig. 1a and b. Fracturing of SiC powders occurred during ball-milling leading to the formation of a mixture of coarse and fine powder particles, see Fig. 1c. 

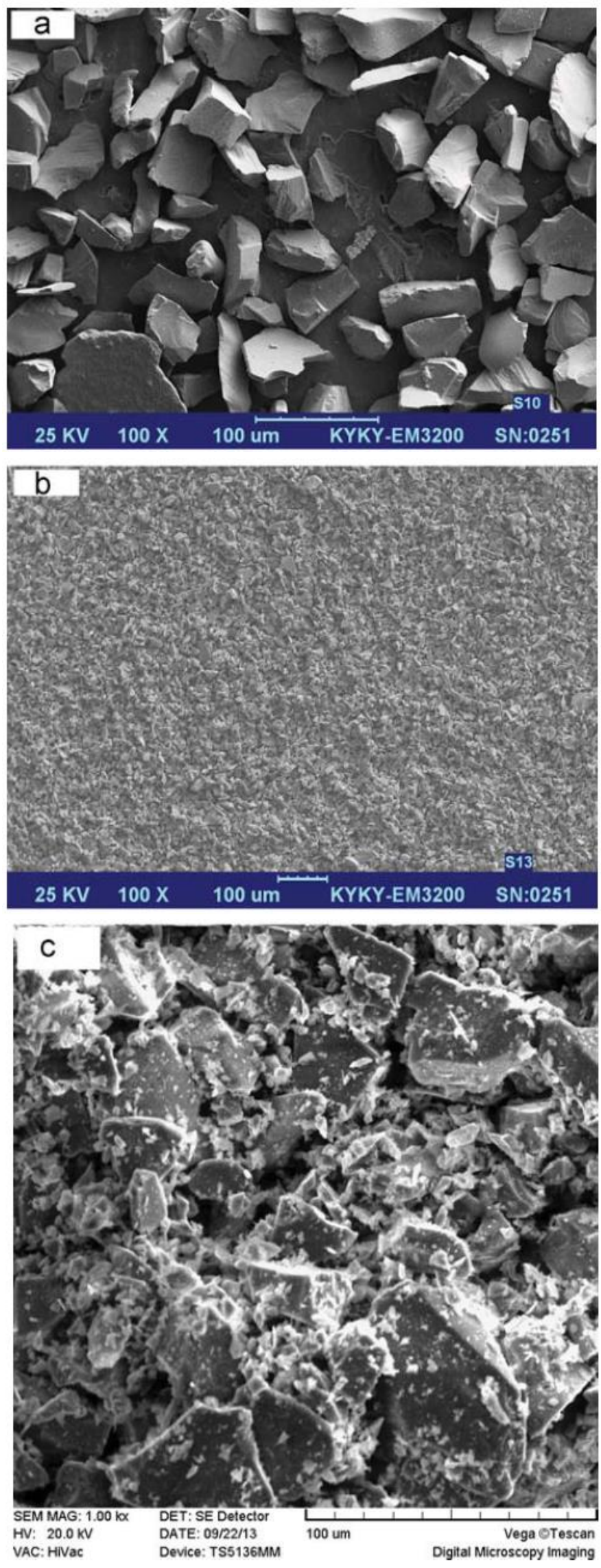

Fig. 1. The SEM morphology of as-received (a) $80 \mu \mathrm{m}$ average particle size (coarse powders), (b) $10 \mu \mathrm{m}$ average particle size (fine powders) and (c) the ball-milled powders. 


\subsection{Coating of $\mathrm{SiC}$ particles}

The first step was cleaning the $\mathrm{SiC}$ powders using acetone to remove impurities from the surface. A SiC particulate in acetone loading concentration of $2 \mathrm{~g} / 100 \mathrm{ml}$ was used for each sample batch prepared in this work. Fig. 2 shows the flow chart of the Ni- P coating procedure. As can be seen in this figure, the powders were pre-treated in three steps after washing in acetone followed by progressive drying and electroless decomposition.

Table 1 presents the details of the chemicals used for pretreatment of the SiC powders, showing that all three steps were conducted at room temperature followed by drying at $90{ }^{\circ} \mathrm{C}$ for $2 \mathrm{~h}$.

The composition and concentration of the materials used for the EN bath for the coating process are presented in Table 2 . All the procedures were carried out with a magnetic stirring speed of $400 \mathrm{rpm}$.

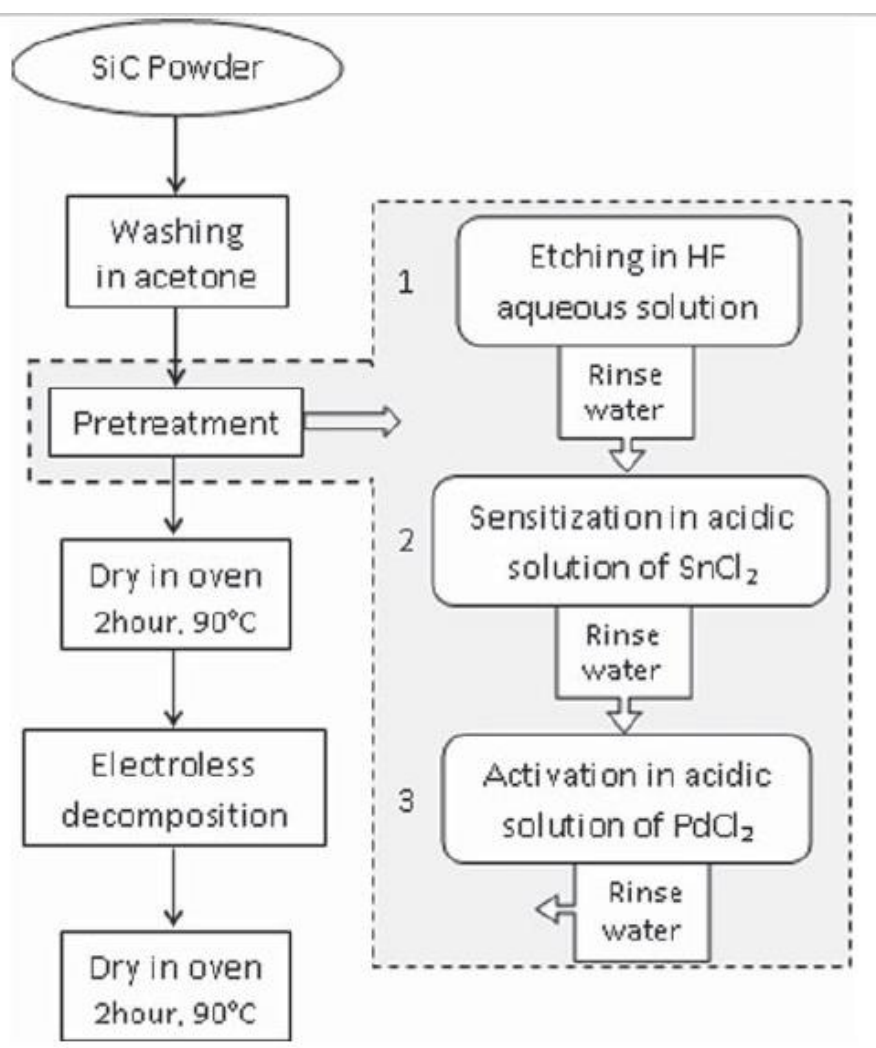

Fig. 2. Flow chart of preparation procedure of Ni-P coated particles.

Table 1

Details of the three $\mathrm{SiC}$ powder pre-treatment conditions, chemicals and washing cycle used.

\begin{tabular}{|c|c|c|c|c|c|}
\hline & & Composition & Concentration & Time & Temperature \\
\hline & Washing & Acetone & $100 \mathrm{ml}$ & $10 \mathrm{~min}$ & \\
\hline \multirow[t]{2}{*}{1} & Coarsening (making a rough surface) & $\begin{array}{l}\mathrm{HF}(40 \%) \\
\mathrm{NaF}\end{array}$ & $\begin{array}{l}100 \mathrm{ml} / 1 \\
2 \mathrm{~g} / 1\end{array}$ & $10 \mathrm{~min}$ & $25^{\circ} \mathrm{C}$ \\
\hline & Washing in distilled water for several times & & & & \\
\hline \multirow[t]{2}{*}{2} & Sensitization & $\begin{array}{l}\mathrm{SnCl}_{2} \\
\mathrm{HCl}(37 \%)\end{array}$ & $\begin{array}{l}10 \mathrm{~g} / \mathrm{l} \\
0.5 \mathrm{ml} / 1\end{array}$ & $15 \mathrm{~min}$ & $25^{\circ} \mathrm{C}$ \\
\hline & Washing in distilled water for several times & & & & \\
\hline \multirow[t]{2}{*}{3} & Activation & $\begin{array}{l}\mathrm{PdCl}_{2} \\
\mathrm{HCl}(37 \%)\end{array}$ & $\begin{array}{l}0.05 \mathrm{~g} / 1 \\
0.1 \mathrm{ml} / 1\end{array}$ & $15 \mathrm{~min}$ & $25^{\circ} \mathrm{C}$ \\
\hline & Washing in distilled water for several times & & & & \\
\hline
\end{tabular}


Table 2

Composition of bath used for electroless dopsition of Ni-P coating on $\mathrm{SiC}$ particles.

\begin{tabular}{lllc}
\hline Role in bath & Composition & & Concentration \\
\hline Main salt & Nickel sulfate & $\mathrm{NiSO}_{4} \cdot 6 \mathrm{H}_{2} \mathrm{O}$ & $25 \mathrm{~g} / 1$ \\
Reducing agent & Sodium hypophosphite & $\mathrm{NaH}_{2} \mathrm{PO}_{2} \cdot \mathrm{H}_{2} \mathrm{O}$ & $27.6 \mathrm{~g} / 1$ \\
Complexing agent & Tri-sodium citrate & $\mathrm{C}_{6} \mathrm{H}_{5} \mathrm{Na}_{3} \mathrm{O}_{7} \cdot 2 \mathrm{H}_{2} \mathrm{O}$ & $46 \mathrm{~g} / 1$ \\
Buffering agent & Acid boric & $\mathrm{H}_{3} \mathrm{BO}_{3}$ & $26 \mathrm{~g} / 1$ \\
pH adjuster & Sodium hydroxide & $\mathrm{NaOH}^{\mathrm{O}}$ & $\mathrm{To}$ adjust $\mathrm{pH}$ \\
SiC powder & & & $0.5 \mathrm{~g} / 100 \mathrm{ml}$ \\
\hline
\end{tabular}

\begin{tabular}{|c|c|c|c|c|}
\hline Sample & $\begin{array}{l}\mathrm{SiC} \\
\text { particle size }\end{array}$ & $\mathrm{pH}$ & Temperature $\left({ }^{\circ} \mathrm{C}\right)$ & $\begin{array}{l}\text { Etching } \\
\text { treatment }\end{array}$ \\
\hline $\mathrm{S}_{1}$ & \multirow{4}{*}{$80 \mu \mathrm{m}$} & 9 & 70 & - \\
\hline $\mathrm{S}_{2}$ & & 9 & 70 & \multirow{3}{*}{$\cdot$} \\
\hline $\mathrm{S}_{3}$ & & 8 & 60 & \\
\hline $\mathrm{S}_{4}$ & & 8 & 50 & \\
\hline $\mathrm{S}_{5}$ & \multirow{4}{*}{$10 \mu \mathrm{m}$} & 9 & 70 & - \\
\hline $\mathrm{S}_{6}$ & & 9 & 70 & \multirow{3}{*}{ * } \\
\hline$\overline{\mathrm{S}_{7}}$ & & 8 & 60 & \\
\hline $\mathrm{S}_{8}$ & & 8 & 50 & \\
\hline $\mathrm{S}_{9}$ & \multirow{4}{*}{ Ball-milled } & 9 & 70 & - \\
\hline $\mathrm{S}_{10}$ & & 9 & 70 & \multirow{3}{*}{ * } \\
\hline $\mathrm{S}_{11}$ & & 8 & 60 & \\
\hline$\overline{S_{12}}$ & & 8 & 50 & \\
\hline
\end{tabular}

Table 3 shows the condition of the samples fabricated in this study. As this table indicates, four important parameters were studied. Some samples were also prepared without etching treatment in order to investigate the etching treatment effect. Also, two temperatures and several $\mathrm{pH}$ values were selected for all three forms of $\mathrm{SiC}$ particles.

\subsection{Characterization}

Two terms of deposition rate and mass gain percent were calculated in accordance with Eqs. (1) and (2):

$$
\begin{aligned}
& \text { Mass gain }(\%)=\left[\frac{\left(W_{\mathrm{f}}-W_{\mathrm{i}}\right.}{W_{\mathrm{m}}}\right] \times 100 \\
& \text { Deposition rate }=\left[\frac{\left(W_{\mathrm{f}}-W_{\mathrm{i}}\right.}{t}\right] \times 100
\end{aligned}
$$

where $\mathrm{W}_{\mathrm{f}}$ is the weight of coated $\mathrm{SiC}$ powders, $\mathrm{W}_{\mathrm{i}}$ is initially weight of $\mathrm{SiC}$ powders, $\mathrm{W}_{\mathrm{m}}$ is the weight of $\mathrm{Ni}-\mathrm{P}$ in the bath that could be deposited on the particles, and $\mathrm{t}$ is the time of deposition, which was evaluated after the $\mathrm{pH}$ reached to a constant value.

As mentioned, the EN deposited coating could avoid the reaction between ceramic particles and metallic matrix such as aluminum during fabrication of metal matrix composites. In order to evaluate the effect of the EN coating on reaction between the coated Sic particles and the aluminum matrix, the same weight of aluminum powder and EN SiC particles was mixed and 
exposed to a differential scanning calorimeter ( DSC ) analysis. Also, DSC analysis was carried out to detect the phase transformation during an ascending temperature profile. A Netzsch STA 409 (Germany) analyzer with a maximum working temperature of $15001 \mathrm{C}$ was used for these measurements with high-purity corundum used as a reference. Powder samples of E30 mg were loaded and pressed into an alumina crucible, which does not react with the powder, and heated up in an inert argon atmosphere at rate of $101 \mathrm{C} / \mathrm{min}$. It should be noted that a microstructural study was applied to assess if the coating layer could be retained on the ceramic particles after incorporation into the molten aluminum.

For this purpose, a specific amount of pure aluminum was melted and stirred for 6 min using a graphite stirrer at $680{ }^{\circ} \mathrm{C}$ and simultaneously the Ni coated $\mathrm{SiC}$ particles were incorporated into the molten metal. After this time, the composite was solidified by pouring into a steel mold.

Samples $\mathrm{S}_{2}$ and $\mathrm{S}_{4}$ of EN SiC powders were exposed to X-ray analysis (Bruker's D8 advance system, Germany) using $\mathrm{Cu} K \alpha(\lambda=0.15405 \mathrm{~nm})$ radiation. X-ray phase analysis of the coated particles was conducted to detect if any other phases were formed and present besidesthe Ni-P and $\mathrm{SiC}$ phases. Also, the peak intensity of these phases was compared for $\mathrm{S}_{2}$ and $\mathrm{S}_{4}$ to detect if the $\mathrm{Ni}-\mathrm{P}$ coating would reduce the $\mathrm{SiC}$ phase intensity. Microstructural investigations were performed using two kinds of scanning electron microscope (SEM, Cam Scan Mv2300, equipped with EDAX analysis and SEM, KYKY-EM3200).

\section{Results and discussion}

Fig. 3 shows the effect of etching pre-treatment on the mass gain percent of coarse, fine, and ball milled powders. The largest mass gain was observed for etched coarse SiC powders in which a $60 \%$ increase in mass was recorded compared to the non-etched powder. This figure indicates that no considerable change in mass gain $\%$ was observed for both fine and ballmilled powders after etching pre-treatment. A higher value of mass gain $\%$ was obtained for $S_{2}$ compared to $S_{1}$, which shows that the growth mechanism of deposited nickel changed after etching pre-treatment. From these results it can be concluded that by increasing the specific surface area of the powders, the effect of etching pre-treatment became negligible.

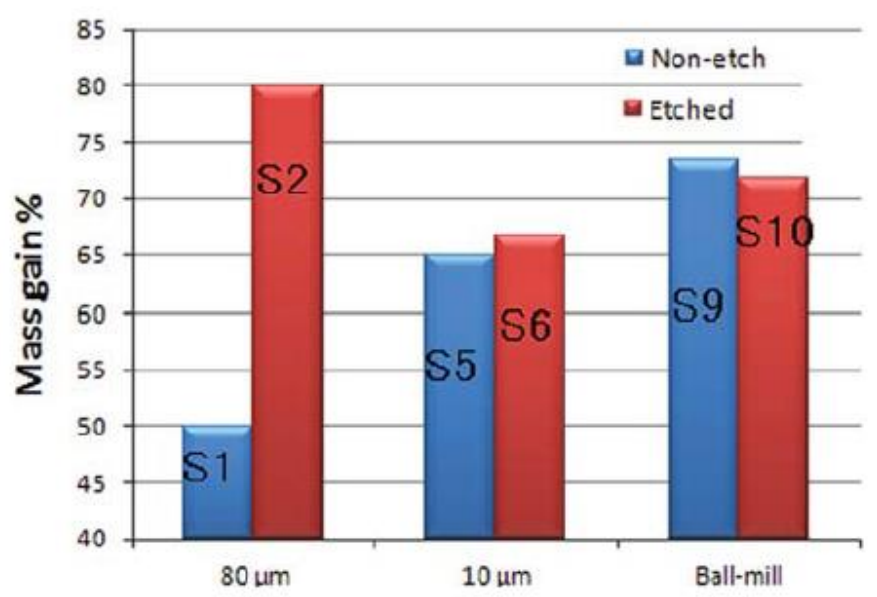

Fig. 3. Effect of etching process on mass gain $\%$ of the samples. 

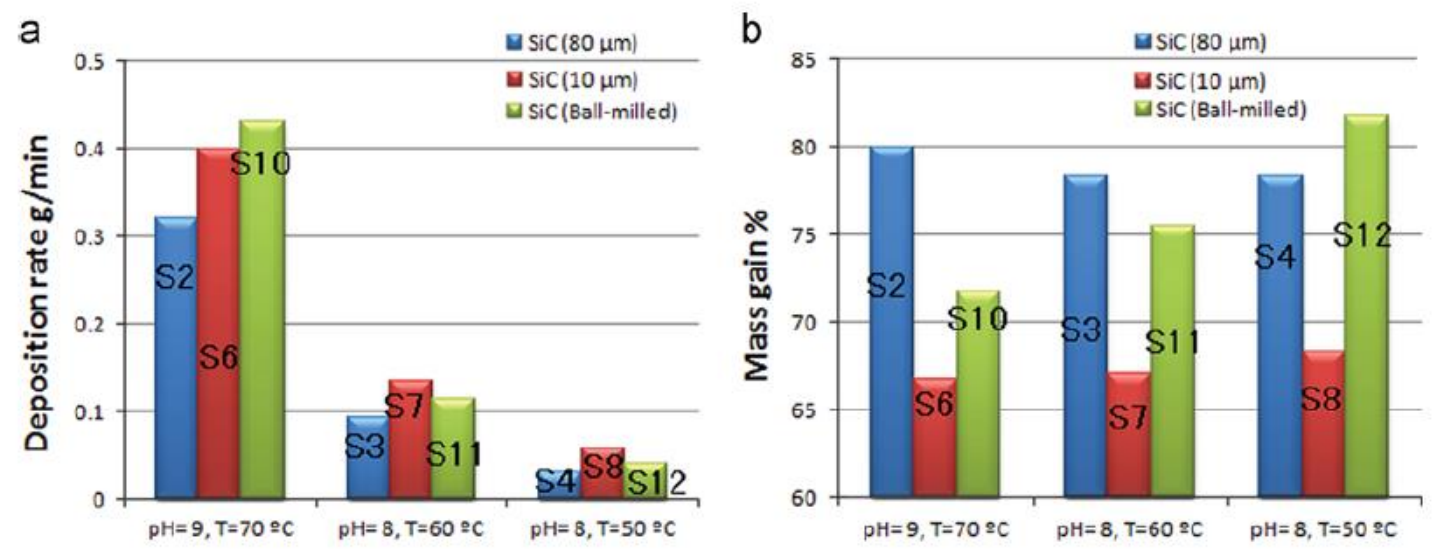

\begin{tabular}{llll}
\multicolumn{4}{c}{ The values of deposition time for the samples } \\
\cline { 2 - 4 } conditions & $\mathrm{SiC}(80 \mu \mathrm{m})$ & $\mathrm{SiC}(10 \mu \mathrm{m})$ & $\mathrm{SiC}$ (Ball-milled) \\
\hline $\mathrm{pH}=9, \mathrm{~T}=70^{\circ} \mathrm{C}$ & $1.5 \mathrm{~min}$ & $1 \mathrm{~min}$ & $1 \mathrm{~min}$ \\
$\mathrm{pH}=8, \mathrm{~T}=60^{\circ} \mathrm{C}$ & $5 \mathrm{~min}$ & $3 \mathrm{~min}$ & $4 \mathrm{~min}$ \\
$\mathrm{pH}=8, \mathrm{~T}=50^{\circ} \mathrm{C}$ & $15 \mathrm{~min}$ & $7 \mathrm{~min}$ & $12 \mathrm{~min}$ \\
\hline
\end{tabular}

Fig. 4. Effect of $\mathrm{pH}$ and bath temperature on mass gain \% and deposition rate.

Fig. 4 shows the effect of $\mathrm{pH}$ and bath temperature on mass gain $\%$ and deposition rate of coarse, fine and ball-milled samples. The results in Fig. 4a show that there was a significant reduction of deposition rate at reduced $\mathrm{pH}$ and bath temperature. As can be seen, the deposition times of the etched coarse and ball-milled powders increased from 1.5 to $15 \mathrm{~min}$ and 1 to $12 \mathrm{~min}$, respectively, by decreasing the $\mathrm{pH}$ and bath temperature. This time was not as significantly increased for the etched fine powders, in which just a 6 min increase was observed (from $1 \mathrm{~min}$ to $7 \mathrm{~min}$ ) by decreasing the $\mathrm{pH}$ and bath temperature. Fig. 4b shows that the mass gain variation was not as significantly affected by variation in the $\mathrm{pH}$ and bath temperature for the as received $\mathrm{SiC}$ powders (both coarse and fine powders); whereas by decreasing the $\mathrm{pH}$ and bath temperature, a notable increase in mass gain $\%$ was recorded for the ball-milled powders. It can be observed that the least amount of mass gain $\%$ occurred for the fine as received powders under all three processing conditions (see Fig. 4b). By reduction of $\mathrm{pH}$ and bath temperature, the mass gain $\%$ of the ball-milled powders was higher than that of the coarse powders. The maximum amount of mass gain $\%$ at about $81 \%$ was obtained for ball-milled samples at $\mathrm{pH} 8$ and bath temperature $=50{ }^{\circ} \mathrm{C}$. In conclusion, three important points could be inferred from what shown in Fig. 4. Firstly, by reduction of $\mathrm{pH}$ and bath temperature the deposition time will be increased for all types of powders. Secondly, in contrast with ball-milled powders, variations of $\mathrm{pH}$ and bath temperature did not significantly change the mass gain \% of fine and coarse powders.

Thirdly, on the basis of these results, the actual amount of the metal layer deposited onto the ceramic surface could not be quantitatively verified. This latter conclusion is due to the fact that the ED process might lead to the formation metal clusters, which are separated from the ceramic surface.

In order to evaluate the results of mass gain $\%$ and deposition rate, SEM images were used as well as EDAX analysis. Fig. 5a shows an SEM image of sample $S_{1}$ (coarse powders), which was not exposed to etching pre-treatment. Some uncoated parts could be seen on the powder surfaces, and it seems that micron-cracks were present on some parts of the powder surfaces. However, the coating layer seems to be very thin and have good mechanical bonding in many parts between the coating and the ceramic particles. Another important result noted here is that there was no formation of segregated nickel globules and clusters independent of the 
particles for this sample. Fig. 3 shows that the mass gain $\%$ for this sample was much lower than those of the other samples. The line EDAX analysis on the particle surface with some uncoated sections, indicated as expected the presence of nickel in coated regions. Fig. $5 \mathrm{~b}$ shows the microstructure of EN coated $S_{2}$ pertaining to coarse powders that were exposed to the etching pre-treatment using HF acid.

This process led to an increase in the number of nucleation sites and removes the $\mathrm{SiO}_{2}$ layer on the surface, enhancing the deposition velocity, resulting in the formation of segregation of nickel deposits. In fact, nickel in some cases did not have enough time for deposition and attachment to the SiC surface. The white rectangles in this figure show flakes of EN coating detached from the ceramic surfaces. Fig. 3 shows that the maximum amount of mass gain $\%$ was obtained for this sample. It seems that most of the ceramic powder particles were coated during EN. The intensity of nickel obtained by line EDAX analysis was higher than for that found from the previous sample, which could be due to an increase in the thickness of the coating. Fig. 5c shows the microstructure of the coarse particles (sample $\mathrm{S}_{4}$ ) after etching treatment, coated using the lower bath temperature $\left(50{ }^{\circ} \mathrm{C}\right)$ and $\mathrm{pH}(8)$. The mass gain $\%$ was considerable for this sample (see Fig. 4b). No uncoated parts of the surface could be seen and the thickness and mechanical bonding appeared to be very good. The red rectangles show regions where globular-like segregated nickel deposits were not separated from the particles, indicating good adhesion of the deposited phases for the EN coating.
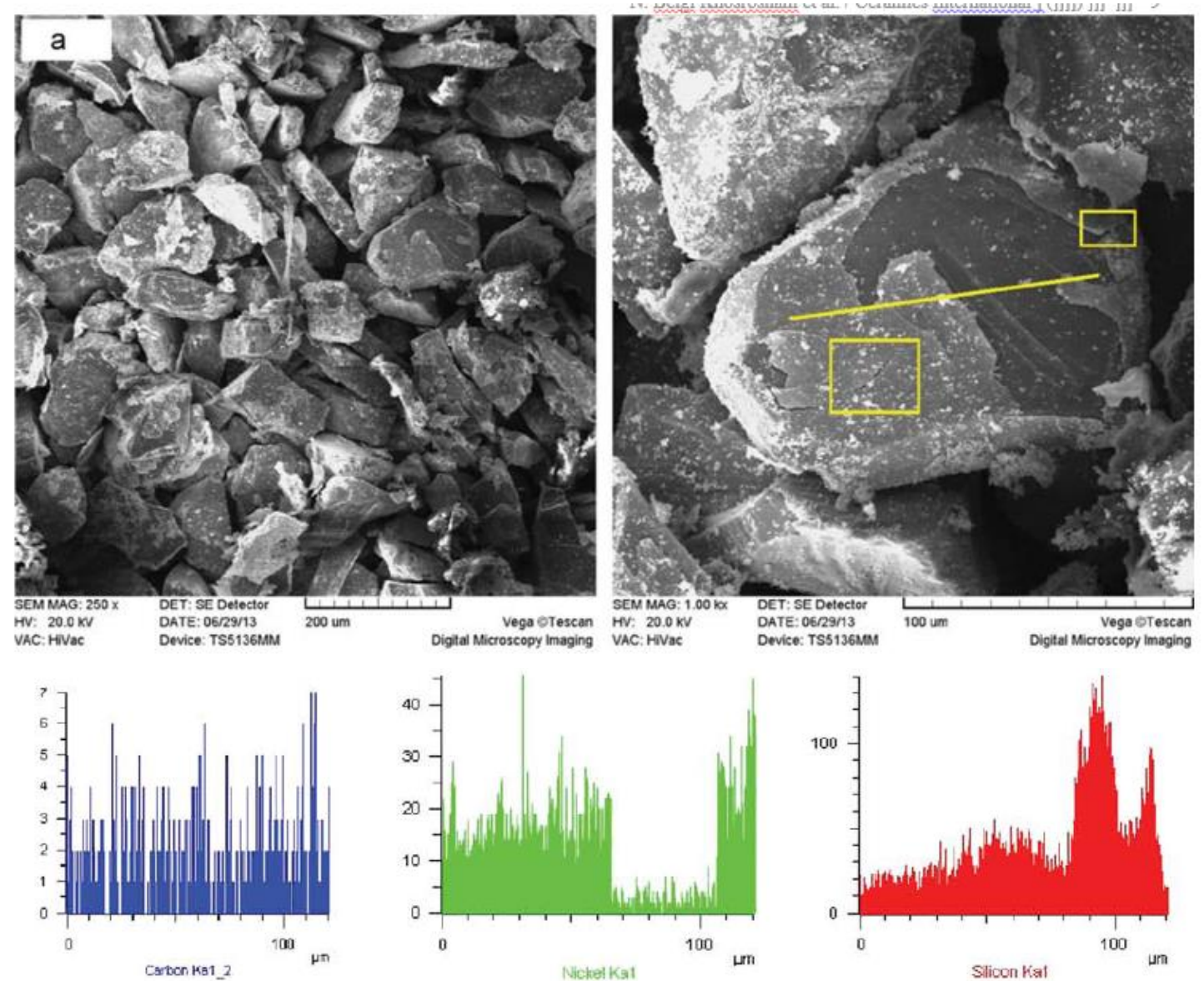
b
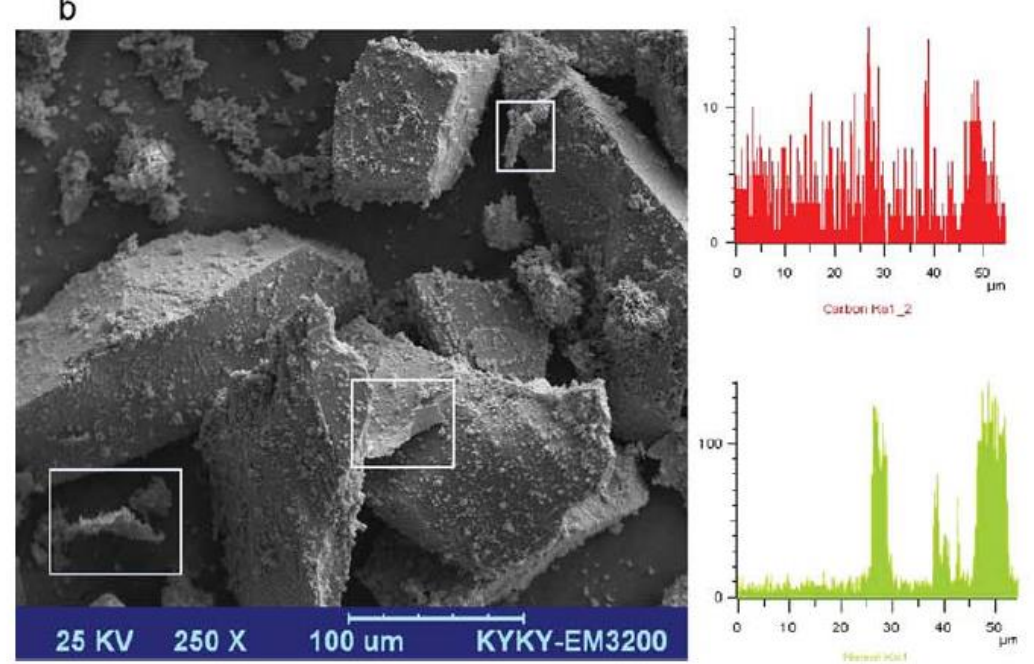
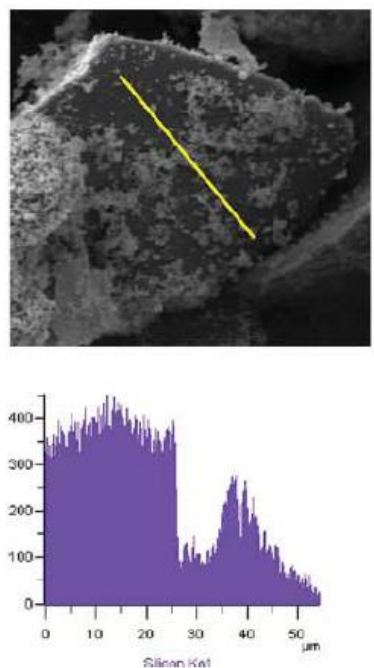

Fig. 5. Low and high magnifications SEM images and EDAX analysis of selected samples: (a) $S_{1}$, (b) $S_{2}$, (c) $S_{4}$, (d) $S_{8}$, (e) $S_{9}$, (f) $S_{10}$, and (g) $S_{12}$.
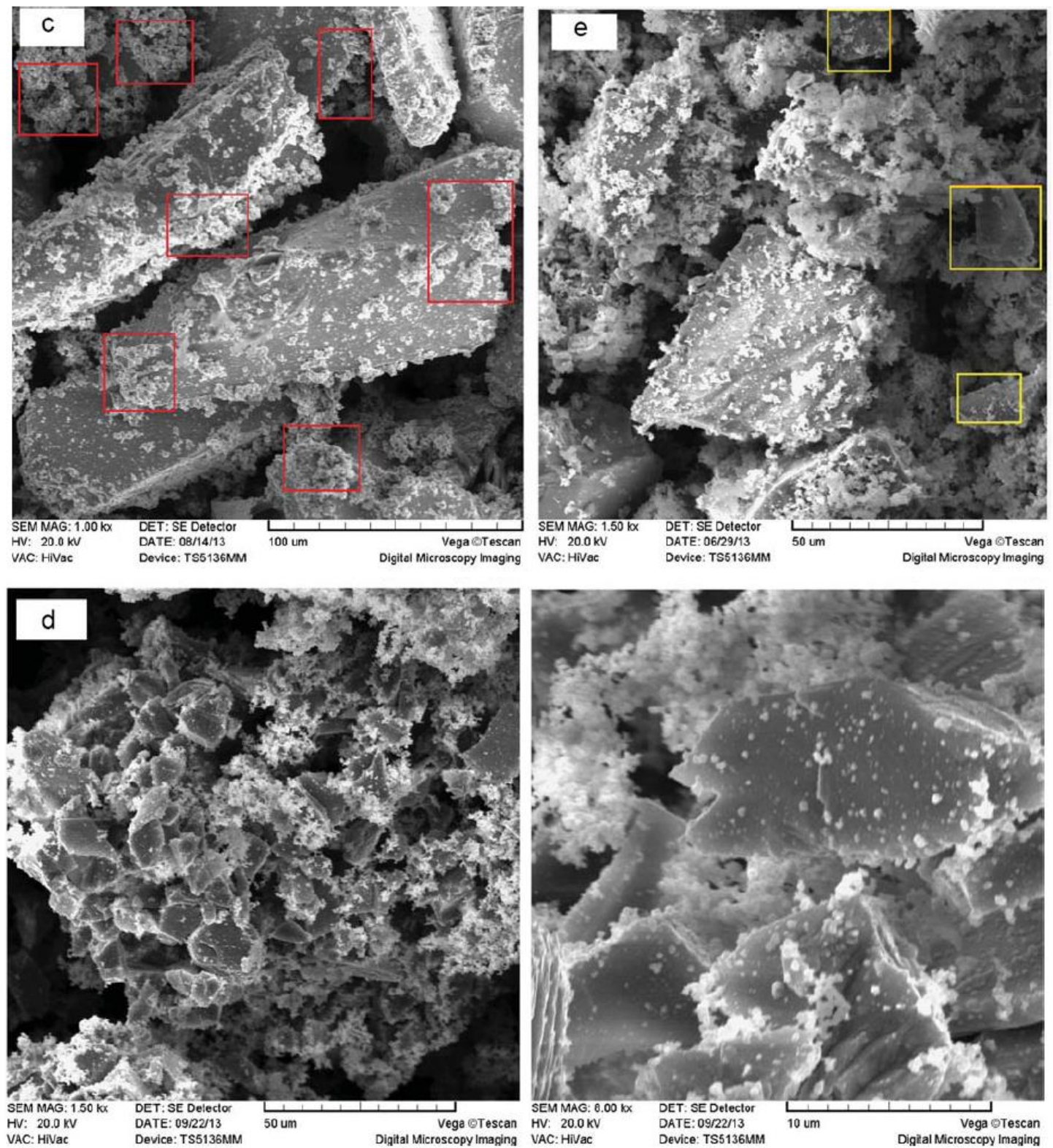

Fig. 5. (continued) 

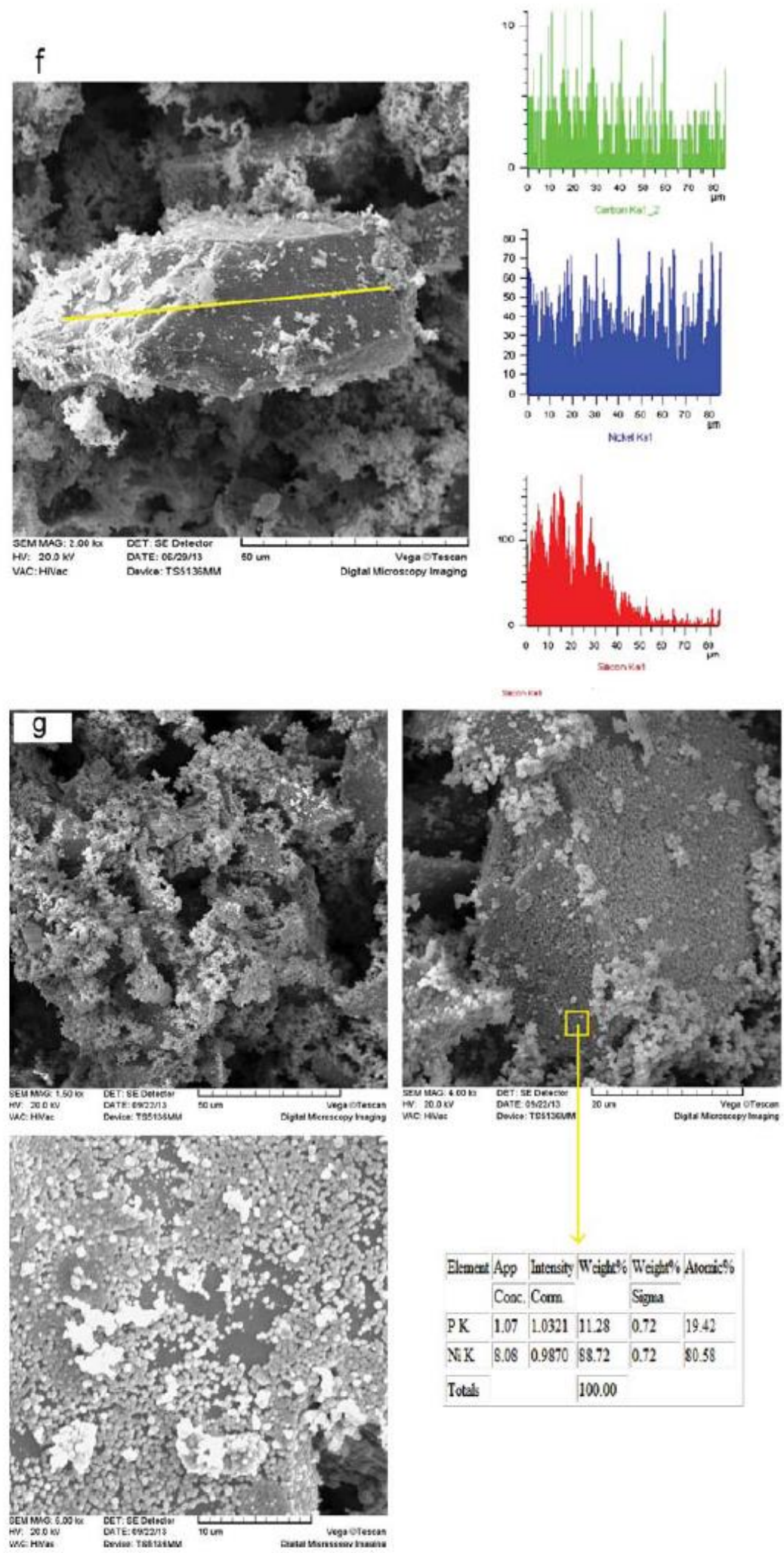

Fig. 5. (continued)

As Fig. 4b indicates, fine SiC powders were not highly coated by EN. Fig. 5d shows that fine etched $\mathrm{SiC}$ powders coated at $\mathrm{pH} 8$ and bath temperature of $50{ }^{0} \mathrm{C}$ were not completely covered by EN coating (sample $\mathrm{S}_{8}$ ). Many nickel-free $\mathrm{SiC}$ surface regions could be observed in Fig. 5d. It seems that the main phenomena during the EN coating of this sample was the 
segregation of nickel clusters and with only some small globules of nickel forming on the surface of the $\mathrm{SiC}$ particle resulting in poor coating quality for this sample. Fig. 5e and $\mathrm{f}$ shows the effect of ball-milling of coarse powders without (sample $S_{9}$ ) and after (sample $S_{10}$ ) etching treatment, respectively, on the morphology and mechanical bonding of EN coating. It can be observed from Fig. 3 that the mass gain $\%$ for this ball milled sample $\left(S_{9}\right)$ was higher than for the coarse and fine powders, and that the etching treatment did not significantly change the mass gain \% value. No continuous adhesive layer of nickel could be observed on the particles for samples $S_{9}$ and $S_{10}$. It seems that a distinctive deposition mechanism has taken place for the ball-milled samples. Fig. 4a indicated that the maximum amount of deposition rate occurred for the ball-milled sample at $\mathrm{pH} 9$ and bath temperature of $701 \mathrm{C}$. Fig. $5 \mathrm{~g}$ and $\mathrm{f}$ shows globules of nickel deposits as separated clusters, which it seems as though they did not have enough time to settle and attached to the particles.

Fig. $5 \mathrm{~g}$ shows the morphology of sample $\mathrm{S}_{12}$, in which coarse powders were ball-milled followed by etching treatment. However, in contrast with $S_{9}$ and $S_{10}$, for this sample, the $\mathrm{pH}$ and bath temperature were 8 and $50{ }^{\circ} \mathrm{C}$, which lead to the highest mass gain $\%$ (see Fig. $4 \mathrm{~b}$ ) and close to the lowest deposition rate (see Fig. 4a). A reduction in deposition rate might cause the deposits to slowly settle on the particle, allowing for a better coating quality with strong mechanical bonding as well as a better uniformity. However, it seems that the presence of nickel separated clusters is inevitable for fine and ball-milled powders. Fig. 5g also shows some nickel free regions on the ceramic surfaces, indicating that the nickel globules were not deposited to completely cover the surface even for this sample.

Table 4 presents a summary of the results for the selected samples of Fig. 5. As regards etching pre-treatment effect, it should be noted that this process has been used to make a rough surface suitable for metal deposition.

\begin{tabular}{|c|c|}
\hline Sample characteristics & Results \\
\hline Coarse powders, $\mathrm{pH} 9, T=70^{\circ} \mathrm{C}$, without etching & Incomplete coating, no segregation of nickel globules, and minimum amount of mass gain $\%$ \\
\hline Coarse powders, $\mathrm{pH} 9, T=70^{\circ} \mathrm{C}$, with etching & High amount of mass gain $\%$, good uniformity, and segregation of nickel globules \\
\hline Coarse powders, $\mathrm{pH} 8, T=50^{\circ} \mathrm{C}$, with etching & $\begin{array}{l}\text { Considerable mass gain } \% \text {, improved mechanical bonding, good uniformity, and adhesion of } \\
\text { segregated nickel globules to the particles }\end{array}$ \\
\hline Fine powders, $\mathrm{pH} 8, T=50^{\circ} \mathrm{C}$, with etching & Low amount of mass gain $\%$, segregation of nickel clusters, poor coating quality \\
\hline Ball-milled, $\mathrm{pH} 9, T=70^{\circ} \mathrm{C}$, without etching & High amount of mass gain $\%$, considerable segregation of nickel clusters, inhomogeneity of coating \\
\hline Ball-milled, $\mathrm{pH} 9, T=70^{\circ} \mathrm{C}$, with etching & High amount of mass gain $\%$, considerable segregation of nickel clusters, inhomogeneity of coating \\
\hline Ball-milled, $\mathrm{pH} 8, T=50^{\circ} \mathrm{C}$, with etching & $\begin{array}{l}\text { Maximum amount of mass gain } \% \text {, better coating quality with stronger mechanical bonding as well as } \\
\text { a better uniformity in comparison with the previous ball-milled samples }\end{array}$ \\
\hline
\end{tabular}

Although both as-received and ballmilled powders have a layer of $\mathrm{SiO}_{2}$ and this layer will be removed for all ranges of powder size after HF addition, the etching process will not be effective for the ball-milled powders. Fig. 1c shows that the ball milling of a brittle ceramic compound made a rough surface during continuous fracturing. The etching process did not seem to contribute to the surface roughness on these samples. As regards fine powders, it should be noted that the etching process was effective however the nickel layer could not be deposited on these particles. It appears that it is not an easy task to coat nickel on fine ceramic powders below $30 \mu \mathrm{m}$ via the ED process.

Fig. 6 shows the XRD patterns of samples $S_{2}$ and $S_{4}$. Figs. $5 b$ and $c$ and 4 show further the EN coating for these samples. Fig. 6 shows the detection of $\mathrm{SiC}, \mathrm{Ni}_{8} \mathrm{P}_{3}, \mathrm{Ni}$, and $\mathrm{P}$ phases (the presence of phosphorous and its compounds was previously reported in EN using hypophosphate compound) in the spectrum from sample $S_{2}$ (see Fig. 6a), while similar peaks and phases were recorded albeit with lower intensity for sample $S_{4}$. 


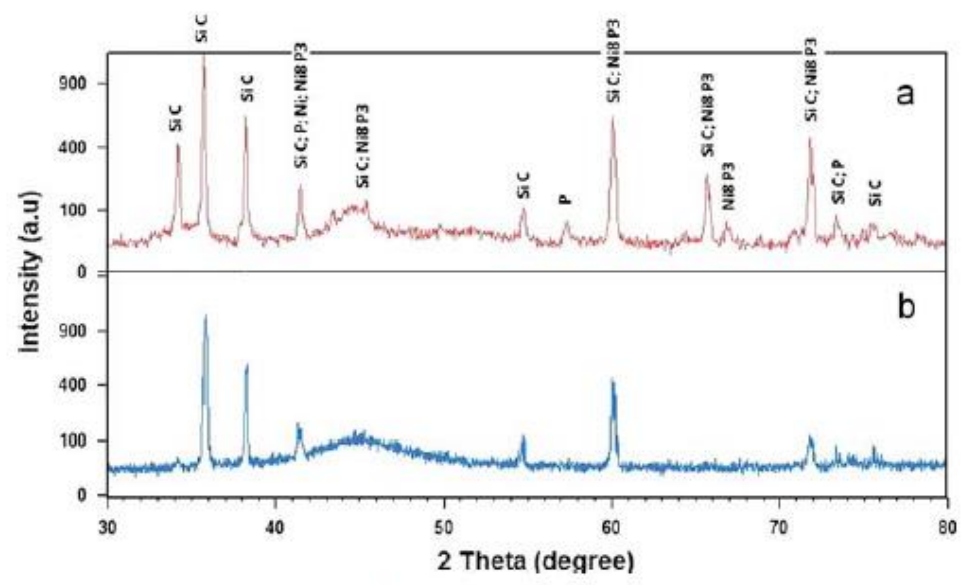

Fig. 6. XRD analysis spectra of samples (a) $S_{2}$ and (b) $S_{4}$.

Previous researchers have indicated that the Ni-P coating is generally deposited in an amorphous form $[10,11,17,18]$. It seems that a much lower deposition rate for $\mathrm{S}_{4}$ compared to $S_{2}$ (from variation in the $\mathrm{pH}$ and temperature), as shown in Fig. 4a, might affect the structure of EN coating to become more nanocrystalline or amorphous. A reduction in ceramic peaks intensity of XRD patterns after metallic coating was also observed by Zhu et al. [19]. It should be noted that broadening of the XRD reflections in this regard is mainly due to the crystallite size component and not the strain [18].

As mentioned, EN coating is a well-known process in fabrication of aluminum cast metal matrix composites [1-8], which could avoid non-wetting between ceramic particles and aluminum during fabrication of metal matrix composites. Fig. 7 shows the DSC analysis of $\mathrm{Al}-\mathrm{SiC}$ and $\mathrm{Al} / \mathrm{Ni}-\mathrm{P}$ coated $\mathrm{SiC}$ composites.

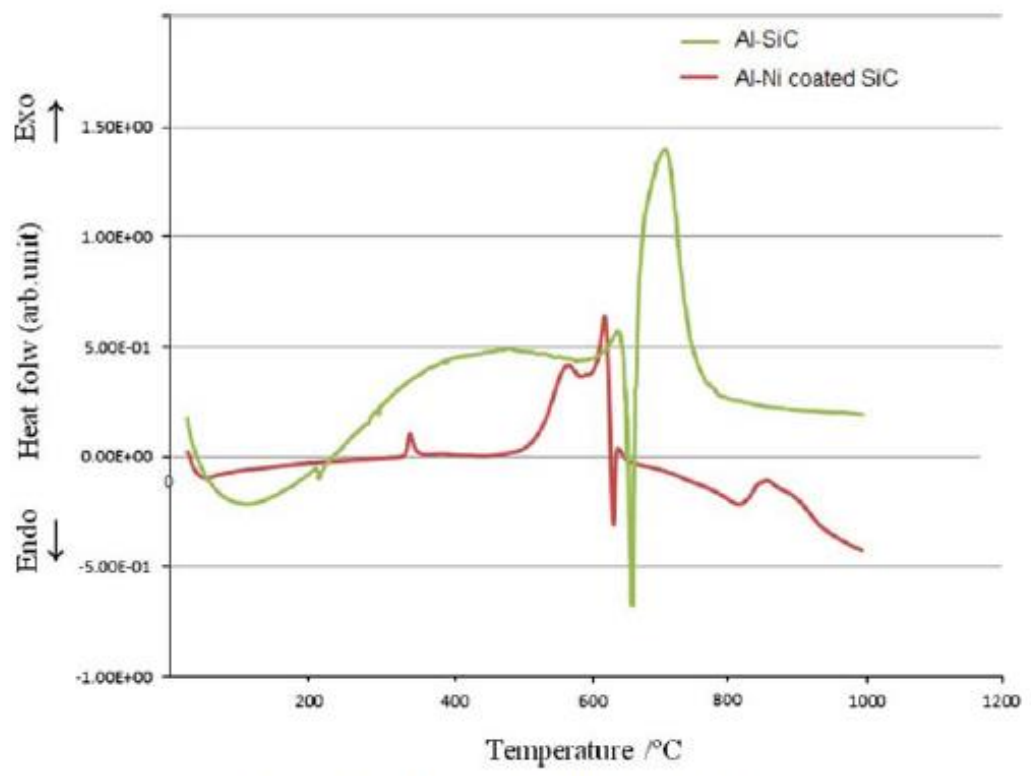

Fig. 7. DSC analysis of Al-SiC and Al/Ni-P coated $\mathrm{SiC}$ composites.

As this figure shows, after the melting peak of the aluminum (endothermic peak), an intensive reaction occurred between aluminum and $\mathrm{SiC}$ at about $7201 \mathrm{C}$ (exothermic peak), which shows that $\mathrm{SiC}$ powders are not thermodynamically stable in the molten aluminum and will react with matrix to form detrimental phase of $\mathrm{Al}_{4} \mathrm{C}_{3}[1,4,5,7]$. After $\mathrm{EN}$ deposition clear 
changes in the DTA response occurred. An exothermic peak, which is related to the crystallization of the electroless nickel coatings, was revealed at about $3501 \mathrm{C}$ [17], while an endothermic peak corresponding to the melting of aluminum was revealed at about $6401 \mathrm{C}$. Two exothermic peaks below the melting point of aluminum were detected for this sample, which our previous studies have shown that these peaks may be related to the reactions between $\mathrm{Ni}$ and $\mathrm{Al}$ to form intermetallic phases of $\mathrm{Al}-\mathrm{Ni}$ bindery systems. Finally, an exothermic peak was revealed at about $8501 \mathrm{C}$, which it seems that this peak is possibly pertaining to the reaction between $\mathrm{Al}$ with uncoated parts of the $\mathrm{SiC}$ particles. The intensity of this exothermic peak is not relevant meaning that there was not an intensive reaction between aluminum and $\mathrm{SiC}$.

This result indicates that cast Al-based matrix composites could be fabricated at even 700$8001 \mathrm{C}$ without $\mathrm{Al}_{4} \mathrm{C}_{3}$ formation using a nickel coating on the reinforcement. However, this conclusion depends on nickel remaining during incorporation and melt stirring. Another important point is the possible formation of $\mathrm{Al}_{3} \mathrm{Ni}_{2}, \mathrm{AlNi}_{3}, \mathrm{Al}_{3} \mathrm{Ni}$, and $\mathrm{AlNi}$ intermetallic phases [1,3-5,7] where nickel coated reinforcement phase was incorporated into the molten aluminum. These two exothermic peaks below the melting of aluminum (see Fig. 7) might show the formation of $\mathrm{NiAl}_{3}$ and/or $\mathrm{Ni}_{2} \mathrm{Al}_{3}$ as reported in the literature [1,3,5,7]. For the purpose of investigating this, the powders of sample $S_{4}$ were incorporated into a melt of pure aluminum using the vortex casting method.

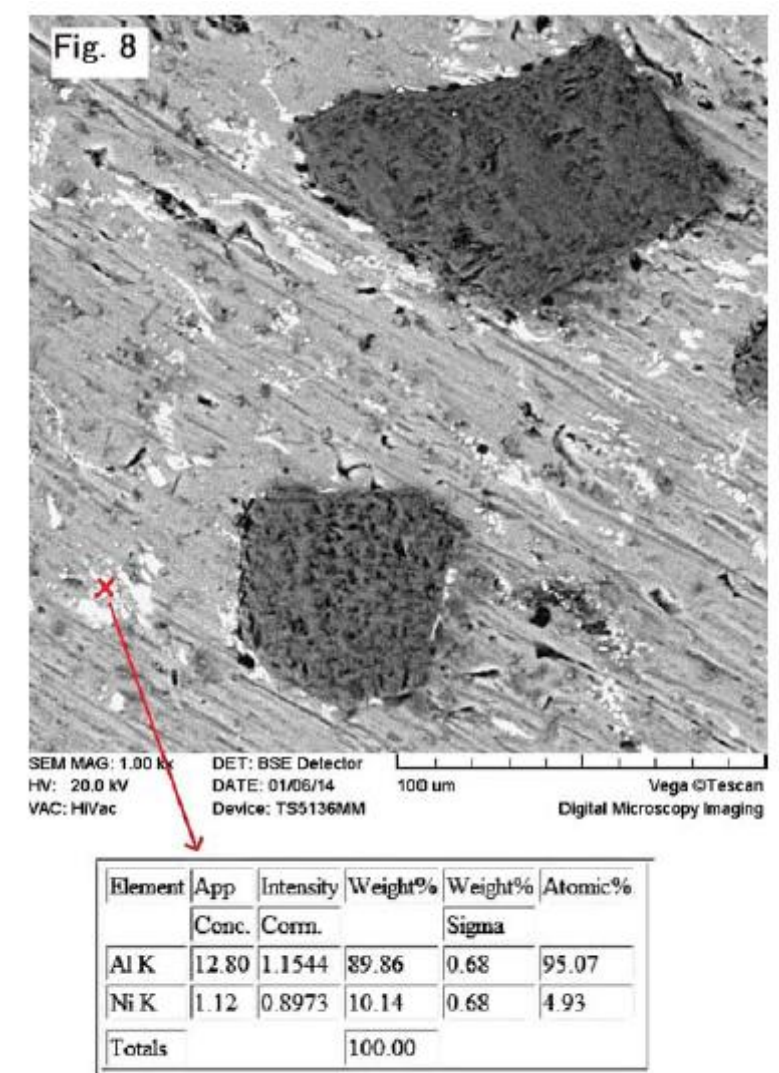

Fig. 8. The SEM/EDAX study of aluminum matrix composite reinforced with Nicoated $\mathrm{SiC}$ particles.

Fig. 8 shows the SEM image of as-cast aluminum matrix composite. As can be seen, two $\mathrm{SiC}$ particles were embedded in the aluminum matrix and a discontinuous layer (in white color) was present around the particles. Point EDAX analysis of this layer is also shown in 
Fig. 8. This analysis shows the presence of about $5 \mathrm{wt} \% \mathrm{Ni}$ in these phases. From this figure, it can be seen that the nickel layer did not completely remain on the surface of ceramic particles during their incorporation and stirring. Chemical reaction between aluminum and $\mathrm{SiC}$ might therefore take place at the uncoated surface when the casting temperature is higher than $7001 \mathrm{C}$.

\section{Conclusions}

This study was undertaken to evaluate the effects of EL coating parameters, SiC particle size and morphology on the coating uniformity and mechanical bonding at $\mathrm{SiC} / \mathrm{Ni}-\mathrm{P}$ interface. From the experimental results, the following conclusions were determined.

1- Etching pre-treatment using hydrofluoric (HF) acid was very effective on enhancing the mechanical bonding at the interface, however, a considerable mass gain was revealed after etching pre-treatment only for large-sized $\mathrm{SiC}$ particles.

2- The maximum amount of mass gain was obtained for bath temperature and $\mathrm{pH}$ of 5072 $1 \mathrm{C}$ and 870.2, respectively.

3- It was shown that a better uniformity and mechanical bonding were obtained for $\mathrm{SiC}$ particles with average particle size of $80 \mu \mathrm{m}$ rather than of $10 \mu \mathrm{m}$.

4- Ball milling of SiC particles (with the average particle size of $80 \mu \mathrm{m}$ ) for $1 \mathrm{~h}$ led to the formation of a multi-modal particle size distribution, and therefore, a non-uniform distribution of coating quality was obtained for the particles. Large-sized SiC particles after ball milling were more completely covered by Ni-P coating compared to the smaller fragmented particles.

5- It was noted that a decreasing in ceramic particle size in Ni-P EL coating might lead to formation of the Ni-P segregated clusters and ceramic particles with many uncoated parts.

6- The maximum amounts of mass gain and deposition rate were obtained for ball-milled and $80 \mu \mathrm{m}$ particles.

7- The XRD results indicated that the intensity of $\mathrm{SiC}$ peaks was decreased by decreasing the $\mathrm{pH}$ value possibly due to a reduction in crystallite size.

8- The DSC and XRD results indicated that the $\mathrm{Ni}-\mathrm{P}$ coating was deposited in an amorphous form. Also, it was found that the presence of $\mathrm{Ni}-\mathrm{P}$ coating on $\mathrm{SiC}$ particles could lead to a reaction between nickel and aluminum in solidstate form before the melting of aluminum. The presence of the coating shifted the reaction of aluminum and $\mathrm{SiC}$ to a higher temperature and with a considerably lower intensity.

\section{References}

[1] A. Urena, J. Rams, M. Campo, M. Sanchez, Effect of reinforcement coatings on the dry sliding wear behaviour of aluminum/SiC particles/ carbon fibres hybrid composites, Wear 266 (2009) 1128-1136. 
[2] C.S. Ramesh, R. Keshavamurthy, B.H. Channabasappa, A. Ahmed, Microstructure and mechanical properties of $\mathrm{Ni}-\mathrm{P}$ coated $\mathrm{Si}_{3} \mathrm{~N}_{4}$ reinforced Al6061 composites, Mater. Sci. Eng. A 502 (2009) 99-106.

[3] J. Pázmán, V. Mádai, J. Tóth, Z. Gácsi, Investigation of the electroless nickel plated SiC particles in metal matrix composites, Powder Metall. Prog. 10 (2010) 102-109.

[4] C.A. Leon-Patiño, R.A. Drew, Role of metal interlayers in the infiltration of metalceramic composites, Curr. Opin. Solid State Mater. Sci. 9 (2005) 211-218.

[5] B. Dikici, C. Tekmen, M. Gavgali, U. Cocen, The effect of electroless Ni coating of SiC particles on the corrosion behavior of A356 based squeeze cast composite, Stroj. Vestn. J. Mech. Eng. 57 (2011) 11-20.

[6] F. Kretz, Z. Gacsi, J. Kovacs, T. Pieczonka, The electroless deposition of nickel on SiC particles for aluminum matrix composites, Surf. Coat. Technol. 180 (2004) 575-579.

[7] C.A. Leon, R.A.L. Drew, The influence of nickel coating on the wettability of aluminum on ceramics, Composites Part A: Appl. Sci. Manuf. 33 (2002) 1429-1432.

[8] L. Dobrzański, M. Kremzer, J. Konieczny, The influence of Ni-P layer deposited onto $\mathrm{Al}_{2} \mathrm{O}_{3}$ on structure and properties of $\mathrm{Al}-\mathrm{Al}_{2} \mathrm{O}_{3}$ composite materials, J. Achiev. Mater. Manuf. Eng. 46 (2011) 147-153.

[9] A. Kilicarslan, F. Toptan, I. Kerti, Electroless nickel-phosphorus coating on boron carbide particles, Mater. Lett. 76 (2012) 11-14.

[10] M. Hajizamani, A. Alizadeh, N. Ehsani, Deposition of a $\mathrm{Ni}_{3} \mathrm{P}$ nano-scale layer on $\mathrm{B}{ }_{4} \mathrm{C}$ nanoparticles by simple electroless plating in an acidic bath, Appl. Nanosci. 2 (2012) 417-421.

[11] G.V. Babu, M. Palaniappa, M. Jayalakshmi, K. Balasubramanian, Electroless Ni-P coated on graphite as catalyst for the electro-oxidation of dextrose in alkali solution, J. Solid State Electrochem. 11 (2007) 1705-1712.

[12] A. Brenner, G.E. Riddell, Nickel plating on steel by chemical reduction, J. Res. Natl. Bur. Stand. 37 (1946) 31-34.

[13] G. Zou, M. Cao, H. Lin, H. Jin, Y. Kang, Y. Chen, Nickel layer deposition on SiC nanoparticles by simple electroless plating and its dielectric behaviors, Powder Technol. 168 (2006) 84-88.

[14] E. Rudnik, K. Kokoszka, J. Łapsa, Comparative studies on the electroless deposition of $\mathrm{Ni}-\mathrm{P}, \mathrm{Co}-\mathrm{P}$ and their composites with SiC particles, Surf. Coat. Technol. 202 (2008) $2584-2590$.

[15] M. Kang, J. Man Kim, J.W. Kim, Y.K. Kim, H. Chung, J.E. Yie, Simple and fast microwave-enhanced wet etching of $\mathrm{SiC}$ particles for electroless $\mathrm{Ni}-\mathrm{P}$ plating, Surf. Coat. Technol. 161 (2002) 79-85.

[16] C. Suryanarayana, Mechanical alloying and milling, Prog. Mater. Sci. 46 (2001) 1-184.

[17] J.N. Balaraju, T.S.N.S Narayanan, S.K. Seshadri, Structure and phase transformation behaviour of electroless Ni-P composite coatings, Mater. Res. Bull. 41 (2006) 847-860.

[18] N.M. Martyak, K. Drake, Peak-profile analysis of electroless nickel coatings, J. Alloys Compd. 312 (2000) 30-40.

[19] S. Zhu, L. Tang, Z. Cui,Coating, Different thickness nickel-boron nanolayers onto boron carbide particles, Surf. Coat. Technol. 205 (2011) 2985-2988. 